\title{
Profil Adenokarsinoma Kolon di RSUP Prof Dr. R. D. Kandou dan Siloam Hospitals Periode Januari 2016 - Juni 2017
}

\author{
${ }^{1}$ Rivia P. Pantow \\ ${ }^{2}$ Bradley J. Waleleng \\ ${ }^{2}$ Bisuk P. Sedli
}
${ }^{1}$ Program Studi Pendidikan Dokter Fakultas Kedokteran Universitas Sam Ratulangi Manado ${ }^{2}$ Bagian/SMF Ilmu Penyakit Dalam Fakultas Kedokteran Universitas Sam Ratulangi Email: Pricilliapantow@gmail.com

\begin{abstract}
Adenocarcinoma colon is a malignant cancer that occurs in the digestive mucosa of colon to rectum. According to Globocan in 2012, the incidence of colorectal cancer in Indonesia was 12.8 per 100,000 adults with a mortality of $9.5 \%$ of all cancer cases. This study was aimed to determine the profile of colon adenocarcinoma at Prof. Dr. R. D. Kandou Hospital and Siloam Hospital. This was a retrospective descriptive study using medical record data at Endoscopy Center of Prof. Dr. R. D. Kandou Hospital and Siloam Hospital Manado from January 2016 to June 2017. Samples were patients who had colonoscopy and pathological examination performed on them and were diagnosed as colon adenocarcinoma. In this study there were 85 samples: 44 patients of nonadenocarcinoma and 41 patients of adenocarcinoma as the subjects of the study. Most patients were males (26 patients; 63.4\%), aged 46-60 years old (16 patients), and Minahasan ethnic group (40 patients). Most cancers were adenocarcinoma type (13 patients), located in the rectum (11 patients). The most common complaint was hematochezia ( 20 patients). Conclusion: Colon adenocarcinoma was most common among males, age group 46-60 years, Minahasan ethnic group, with moderate differentiation type of adenocarcinoma and located in the rectum. The most common complaints was hematochezia.
\end{abstract}

Keywords: adenocarcinoma colon, colonoscopy, pathology anatomical

\begin{abstract}
Abstrak: Adenokarsinoma kolon merupakan salah satu jenis kanker ganas yang terjadi pada epitel mukosa usus besar dari kolon sampai dengan rektum. Berdasarkan data dari Globocan tahun 2012 insiden kanker kolorektal di Indonesia ialah 12,8 per 100.000 penduduk usia dewasa dengan mortalitas 9,5\% dari seluruh kasus kanker. Penelitian ini bertujuan untuk mengetahui profil adeno-karsinoma kolon di RSUP Prof. Dr. R. D. Kandou Manado dan Siloam Hospitals. Jenis penelitian ialah deskriptif retrospektif menggunakan data rekam medik di Pusat Endoskopi RSUP Prof. Dr. R. D. Kandou Manado dan Siloam Hospital Manado periode Januari 2016-Juni 2017 pada pasien yang telah dilakukan kolonoskopi dan pemeriksaan patologi anatomi yang didiagnosis dengan adenokarsinoma kolon. Pada penelitian ini didapatkan 85 pasien; 44 pasien dengan non-adenokarsinoma dan 41 pasien dengan adenokarsinoma yang menjadi subjek penelitian. Mayoritas kasus ialah laki-laki 26 $(63,4 \%)$, kelompok usia 46-60 tahun (16 pasien), ras Minahasa (40 pasien) dengan jenis histopatologi tipe adenokarsinoma diferensiasi sedang (13 pasien) dan lokasi tumor di rektum (11 pasien). Hematokezia merupakan keluhan utama yang paling sering ditemukan (20 pasien). Simpulan: Adenokarsinoma kolon lebih sering didapatkan pada jenis kelamin laki-laki, kelompok usia 46-60 tahun, ras Minahasa dengan jenis histopatologi adenokarsinoma diferensiasi sedang dan keluhan utama hematokezia.
\end{abstract}

Keywords: adenokarsinoma kolon, kolonoskopi, patologi anatomi 
Adenokarsinoma kolon merupakan salah satu jenis kanker ganas yang terjadi pada epitel mukosa saluran cerna kolon sampai dengan rektum. Pemeriksaan histopatologik menun-jukkan hampir semua kanker usus besar ialah adenokarsinoma yang terdiri atas epitel kelenjar. ${ }^{1-4}$

Menurut American Cancer Society, kanker kolorektal merupakan kanker ketiga terbanyak dan merupakan kanker penyebab kematian kedua terbanyak pada populasi laki-laki dan perempuan di Amerika Serikat. ${ }^{5}$ Menurut data dari Globocan 2012, insiden kanker kolorektal di Indonesia ialah 12,8 per 100.000 penduduk usia dewasa, dengan mortalitas $9,5 \%$ dari seluruh kasus kanker. ${ }^{6}$ Indonesia menempati urutan ke-3 kanker kolorektal; hal ini disebabkan oleh karena perubahan pola makan masyarakat Indonesia yang mengikuti pola makan orang Barat (westernisasi) yaitu mengonsumsi makanan yang lebih tinggi lemak serta rendah serat. ${ }^{2}$

Risiko terjadinya kanker kolorektal mulai meningkat setelah usia 40 tahun dan meningkat tajam pada usia 50-55 tahun, dan risiko meningkat dua kali lipat setiap dekade berikutnya. ${ }^{7}$ Sekarang sudah mulai terjadi pergeseran usia. Banyak kanker kolon rektal ditemukan pada usia yang lebih muda; hal ini disebabkan karena gaya hidup yang kurang sehat. ${ }^{2}$

Terdapat beberapa faktor yang menjadi penyebab terjadinya kanker kolorektal antara lain faktor genetik. Berdasarkan studi yang dilakukan sekitar 20\% kasus kanker kolorektal diturunkan secara genetik. Faktor lain yang juga turut berkontribusi terhadap terjadinya kanker kolorektal yaitu kurangnya aktifitas fisik serta obesitas; keduanya paling sering dilaporkan sebagai faktor yang berhubungan dengan kanker kolorektal. Faktor-faktor lain seperti pola makan yang tinggi lemak serta rendah serat, merokok, dan mengonsumsi alkohol secara berlebihan juga meningkatkan risiko terjadinya kanker kolorektal. ${ }^{2}$

Di Indonesia umumnya kasus kanker kolorektal khususnya adenokarsinoma kolon baru diketahui pada saat kanker sudah memasuki stadium yang lebih lanjut. Hal tersebut disebabkan karena kurangnya pengetahuan masyarakat tentang kanker dan baru memeriksakan diri ke pelayanan penyedia kesehatan bila sudah ada gejala yang sangat mengganggu aktifitas. ${ }^{4}$ Pada keadaan ini sangat diperlukan kemoterapi sebagai modalitas pendamping tetapi seringkali kemoterapi tidak memberikan hasil memuaskan dan mengakibatkan efek samping yang buruk terhadap pasien yang intoleran.

Prognosis adenokarsinoma kolon ditentukan oleh stadium kanker, yaitu dilihat dari sejauh mana invasi sel-sel kanker. Semakin lama dibiarkan tanpa pengobatan dan penanganan semakin besar peluang kanker bermestatasis ke organ lain dan akan semakin memperburuk prognosis. ${ }^{1}$

Penelitian ini bertujuan untuk mengetahui profil adenokarsinoma kolon pada pasien yang sudah dilakukan pemerik-saan kolonoskopi di pusat Endoskopi RSUP Prof. Dr. R. D. Kandou dan Siloam Hospital periode Januari 2016 - Juni 2017.

\section{METODE PENELITIAN}

Jenis penelitian yang dilakukan ialah deskriptif retrospektif berdasarkan data rekam medik di Pusat Endoskopi RSUP Prof. Dr. R. D. Kandou Manado dan Siloam Hospital Manado.

Populasi dalam penelitian ini ialah seluruh pasien yang telah melakukan kolonoskopi di RSUP Prof. Dr. R. D. Kandou Manado dan Siloam Hospital Manado periode Januari 2016-Juni 2017. Sampel penelitian ini ialah pasien yang didiagnosis dengan adenokarsinoma kolon di RSUP Prof. Dr. R. D. Kandou Manado dan Siloam Hospital periode Januari 2016-Juni 2017 yang termasuk dalam kriteria inklusi.

Variabel penelitian ialah usia, jenis kelamin, penggolongan patologi-anatomi, keluhan utama, lokasi tumor, riwayat penyakit keluarga, dan ras.

Data penelitian diolah secara manual menggunakan aplikasi Microsoft Excel, dan disajikan dalam bentuk tulisan, gambar, serta tabel distribusi frekuensi. 


\section{HASIL PENELITIAN}

Pada penelitian ini didapatkan data secara keseluruhan terhadap pasien yang telah melakukan kolonoskopi dan memenuhi kriteria inklusi berjumlah 85 sampel; 41 $(48,2 \%)$ pasien dengan adenokarsinoma kolon yang menjadi subjek penelitian dan $44(51,8 \%)$ pasien non-adenokarsinoma, Data diperoleh dari rekam medik di Pusat Endoskopi RSUP Prof. Dr.R. D. Kandou dan Siloam Hospital periode Januari 2016 - Juni 2017 (Gambar 1).

Dari hasil penelitian didapatkan pasien yang didiagnosis dengan adenokarsinoma kolon berjumlah 41 orang; 26 pasien $(63,4 \%)$ berjenis kelamin laki-laki dan 15 pasien $(36,6 \%)$ berjenis kelamin perempuan (Gambar 2).

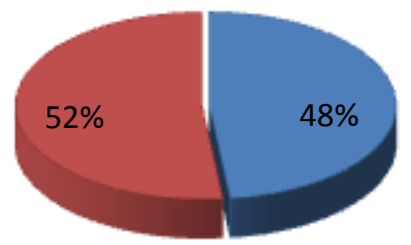

$\square$ Adenokarsinoma Kolon

Gambar 1. Disrtibusi frekuensi pasien dengan adenokarsinoma dan non-adenokarsinoma

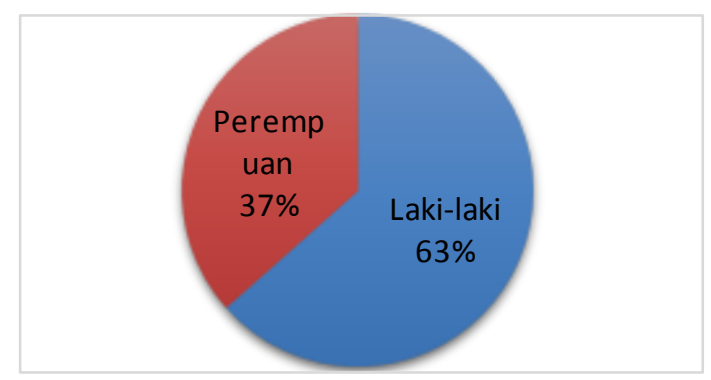

Gambar 2 Disrtibusi adenokarsinoma kolon berdasarkan jenis kelamin

Pada penelitian terhadap 41 orang pasien dengan adenokarsinoma kolon terbanyak ditemukan dalam rentang usia 46-60 tahun sebanyak 16 pasien, dan paling sedikit ditemukan dalam rentang usia 30-45 tahun yaitu sebanyak 5 orang pasien.

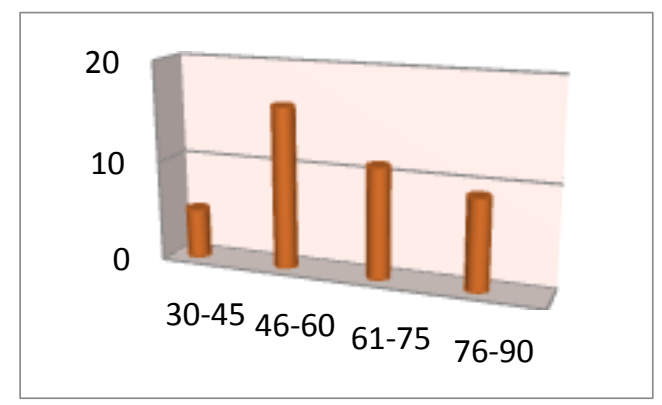

Gambar 3. Disrtibusi adenokarsinoma kolon berdasarkan usia

Berdasarkan hasil pemeriksaan patologi anatomi didapatkan dari 41 orang pasien dengan adenokarsinoma kolon, 13 orang di antaranya memiliki jenis adenokarsinoma diferensiasi sedang, 11 orang jenis adenokarsinoma papiliferum diferensiasi sedang, 3 orang jenis adenokarsinoma diferensiasi berat, 6 orang jenis adenokarsinoma, dan 8 orang jenis adenokarsinoma papiliferum (Tabel 1)

Tabel 1. Disrtibusi adenokarsinoma kolon berdasarkan pemeriksaan histopatologik

\begin{tabular}{lc}
\hline \multicolumn{1}{c}{\begin{tabular}{c}
\multicolumn{1}{c}{ Penggolongan } \\
Patologi Anatomi
\end{tabular}} & Jumlah \\
\hline $\begin{array}{l}\text { Adenokarsinoma diferensiasi } \\
\text { sedang }\end{array}$ & 13 \\
$\begin{array}{l}\text { Adenokarsinoma papiliferum } \\
\text { diferensiasi sedang }\end{array}$ & 11 \\
Adenokarsinoma diferensiasi & 3 \\
berat & \\
Adenokarsinoma & 6 \\
Adenokarsinoma papiliferum & 8 \\
\multicolumn{1}{c}{ Total } & 41 \\
\hline
\end{tabular}

Letak tumor paling banyak ditemukan di rectum pada 11 pasien, colon descenden pada 8 pasien, colon sigmoid 6 , colon ascenden 6 , rectosigmoid 6 , dan paling sedikit ditemukan pada colon transversum dengan 4 pasien (Tabel 2).

Berdasarkan data dari 41 orang pasien dengan adenokarsinoma kolon ditemukan 39 orang pasien tanpa riwayat penyakit keluarga yang mengalami keganasan kolon dan 3 orang pasien dengan riwayat penyakit keluarga yang mengalami keganasan kolon (Tabel 3). 
Tabel 2. Disrtibusi adenokarsinoma kolon berdasarkan lokasi tumor

\begin{tabular}{lc}
\hline \multicolumn{1}{c}{ Lokasi tumor } & Jumlah \\
\hline Colon ascenden & 6 \\
Colon transversum & 4 \\
Colon descenden & 8 \\
Colon sigmoid & 6 \\
Rectosigmoid & 6 \\
Rectum & 11 \\
Total & 41 \\
\hline
\end{tabular}

Tabel 3. Disrtibusi adenokarsinoma berdasarkan riwayat penyakit keluarga

\begin{tabular}{cc}
\hline $\begin{array}{c}\text { Riwayat } \\
\text { penyakit keluarga }\end{array}$ & Jumlah \\
\hline Disangkal & 39 \\
Ya & 3 \\
Total & 41 \\
\hline
\end{tabular}

Ras yang paling banyak ditemukan pada pasien dengan adenokarsinoma kolon ialah ras Minahasa berjumlah 40 pasien dan yang paling sedikit ialah ras Toli-toli yaitu hanya 1 pasien (Tabel 4).

Tabel 4. Disrtibusi adenokarsinoma berdasarkan ras

\begin{tabular}{cc}
\hline Ras & Jumlah \\
\hline Minahasa & 40 \\
Toli-toli & 1 \\
Total & 41 \\
\hline
\end{tabular}

Pada penelitian terhadap 41 orang pasien dengan adenokarsinoma kolon didapatkan keluhan utama terbanyak yaitu hematokezia dengan jumlah 20 pasien dan keluhan utama terendah yaitu diare dengan jumlah 1 pasien (Gambar 4).

\section{BAHASAN}

Berdasarkan hasil penelitian yang telah dilakukan di Pusat Endoskopi RSUP Prof. Dr. R. D. Kandou dan Siloam Hospitas dengan menggunakan data rekam medik dari pasien yang telah melakukan kolonoskopi pada periode Januari 2016 - Juni 2017 ditemukan hasil 85 orang. Terdapat 41 $(48,2 \%)$ orang di antaranya yang didiagnosis adenokarsinoma kolon berdasarkan hasil pemeriksaan patologi anatomi dan 44

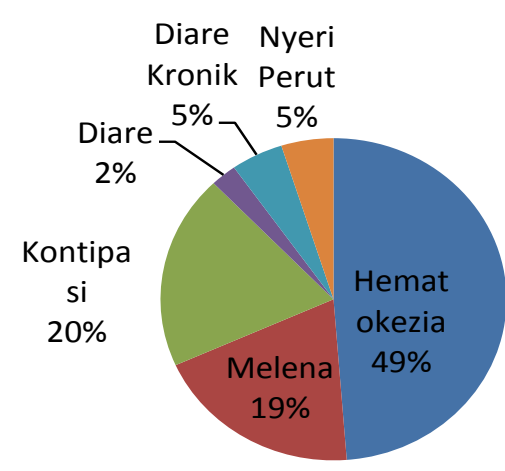

Gambar 4. Disrtibusi adenokarsinoma berdasarkan keluhan utama

$(51,8 \%)$ orang ialah pasien non-adenokarsinoma.

Dari 41 orang pasien yang didiagnosis dengan adenokarsinoma kolon didapatkan hasil $26(63,4 \%)$ orang berjenis kelamin laki-laki dan $15(36,6 \%)$ orang berjenis kelamin perempuan, yang menunjukkan bahwa adenokarsinoma kolon lebih banyak ditemukan pada jenis kelamin laki-laki dibandingkan perempuan. Hasil penelitian ini sejalan dengan hasil penelitian yang dilakukan oleh Hadil dari Fakultas Kedokteran Universitas Andalas Periode Januari 2009 sampai Desember 2011 yng mendapatkan jumlah kasus pada laki-laki lebih tinggi daripada perempuan, yaitu 141 laki-laki $(54,23 \%)$ dan 119 perempuan (45,77\%) dengan total kasus 260 kasus. $^{8}$

Berdasarkan hasil penelitian terhadap 41 orang pasien dengan adenokarsinoma kolon terbanyak ditemukan dalam rentang usia 46-60 tahun sebanyak 16 orang, dan pasien paling sedikit ditemukan dalam rentang usia 30-45 tahun sebanyak 5 orang pasien. Hasil penelitian ini selaras dengan yang dilaporkan oleh Kurniawan ${ }^{9}$ yaitu pada penderita karsinoma kolorektal di Fakultas Kedokteran Universitas Andalas periode tahun 2008 sampai 2012, kasus terbanyak pada kelompok usia tua $>50$ tahun $(57,56 \%)$, dan jika usia dibagi dalam rentang 10 tahun, didapatkan jumlah kasus mencapai puncak pada rentang 51-60 tahun. Peningkatan inisiden di usia tua dapat terjadi karena akumulasi mutasi somatik yang disebabkan berkembangnya neoplas- 
ma dan juga faktor penurunan imunitas seiring bertambahnya usia. Jenis histopatologik yang terbanyak didapatkan pada penelitian ini ialah adenokarsinoma diferensiasi sedang (13 kasus) dan adenokarsinoma papiliferum diferensiasi sedang (11 kasus). Jenis histopatologik yang paling rendah didapatkan ialah adenokarsinoma diferensiasi berat (3 kasus). Juga jenis histopatologik yang lain yaitu adenokarsinoma papiliferum (8 kasus) dan adenokarsinoma (6 kasus). Lokasi tumor terbanyak didapatkan di rectum (11 kasus) dan paling sedikit di colon transversum (4 kasus). Hasil ini selaras dengan yang dilaporkan Zuhaira di RSUP Dr. M. Djamil Padang periode Januari 1996 - Desember 2000 yaitu gambaran histopatologik karsinoma kolorektal tersering ialah adenokarsinoma diferensiasi sedang. ${ }^{8}$

Pada penelitian ini ditemukan 39 pasien adenokarsinoma tidak memiliki riwayat penyakit keluarga dengan keganasan kolon dan terdapat 3 pasien adenokarsinoma yang memiliki riwayat penyakit keluarga dengan keganasan. Genetik merupakan salah satu faktor pencetus adenokarsinoma kolon dan kejadian adenokarsinoma kolon pada usia muda biasanya dipicu oleh faktor genetik. ${ }^{8}$

Ras yang paling banyak ditemukan ialah ras Minahasa yaitu pada 40 pasien dengan adenokarsinoma kolon dan 1 pasien dengan ras Toli-toli.

Hasil penelitian menunjukkan keluhan utama yang paling banyak ditemukan pada pasien dengan adenokarsinoma kolon ialah hematokezia Hematokezia terjadi karena sebagian besar karsinoma yang muncul pada rektum berbentuk ulserasi, sehingga memberikan keluhan berupa buang air besar berdarah.

\section{SIMPULAN}

Berdasarkan hasil penelitian ini dapat disimpulkan bahwa adenokarsinoma kolon paling banyak ditemukan pada jenis kelamin laki-laki, usia 45-60 tahun, ras Minahasa, keluhan utama hematokezia, dengan lokasi tumor di rektum.

Pemeriksaan histopatologik menun- jukkan jenis adenokarsinoma tersering ialah adenokarsinoma diferensiasi sedang.

\section{SARAN}

Bagi pihak tenaga medis RSUP Prof. Dr. R. D. Kandou Manado agar lebih memperhatikan kelengkapan status pasien khususnya mengenai riwayat penyakit keluarga dan hasil pemeriksaan penunjang.

Bagi pihak rumah sakit sebaiknya dilakukan perbaikan dalam pencatatan dan pengarsipan data agar data lebih lengkap, dapat diperoleh dengan mudah, dan tidak ada data pasien yang tidak ditemukan.

Penelitian selanjutnya tentang adenokarsinoma kolon sangat disarankan mengingat kurangnya sumber data dan informasi.

\section{DAFTAR PUSTAKA}

\section{Aminah H, Erida Y, Yulianti H, Hassan HA.} Korelasi ekspresi reseptor vitamin d (VDR) dengan derajat diferensiasi dan stadium adenokarsinoma kolorektal. Bandung: Departemen Patologi Anatomi Fakultas Kedokteran Universitas Padjadjaran Rumah Sakit Dr. Hasan Sadikin Bandung, 2016; p. 124.

2. Komite Penanggulangan Kanker Nasional. Pedoman Nasional Pelayanan Kedokteran Kanker Kolorektal. Jakarta, 2014.

3. Ratnasari D. Perbedaan derajat diferensiasi adenokarsinoma kolorektal pada golongan usia muda, baya, dan tua di RSUP DR. Kariadi Semarang. Medisains. 2012;2:3.

4. Lubis YA, Abdullah M, Hasan I, Suwarto S. Probabilitas temuan kanker kolorektal pada pasien simtomatik berdasarkan unsure-unsur Asia Pasific Colorectal Screening (APCS). Jurnal Penyakit Dalam Indonesia. 2015;25:90-1.

5. American Cancer Society. Key Statistics for Colorectal Cancer. [cited 2017 Aug 17]. Available from: https://www.cancer. org/cancer/colon-rectal-cancer/about/ key-statistics.html.

6. International Agency for Research on Cancer, World Health Organization. Fact sheets by population, incidence, mortality and 5-year prevalence: both sexes Indonesia. [cited 2017 Aug 17]. Available from: http://globocan.iarc.fr/Pages/fact_sheets 
_population.aspx.

7. Anggunan. Hubungan antara usia dan jenis kelamin dengan derajat diferensiasi adenokarsinoma kolon melalui hasil pemeriksaan histopatologi di RSUD Dr. H. Abdul Moeloek Provinsi Lampung [Thesis]. Lampung: Universitas Malahayati; 2014.

8. Hamdi M, Zahari H, Aswiyanti A. Profil karsinoma kolorektal di laboratorium patologi anatomi Fakultas Kedokteran Universitas Andalas. Jurnal Kesehatan Andalas. 2015;4(2):5.

9. Kurniawan T, Zahari A, Aswiyanti A. Hubungan usia dengan kedalaman invasi dan gambaran histopatologi pada penderita karsinoma kolorektal dii Bagian Patologi Anatomi Fakultas Kedokteran UNAND. Jurnal Kesehatan Andalas. 2017;6(2):7. 